\title{
Knowledge and Attitude of Guardians in Management of Avulsion of Primary and Permanent Teeth of Children: A Questionnaire-Based Study
}

\author{
Hira Abbasi, Abhishek Lal, and Ammara Shamim Jaffrani
}

\section{ABSTRACT}

Aims: This study aims to assess knowledge and attitude of guardians in management of dental avulsion of the children.

\begin{abstract}
Materials and Methods: This cross-sectional study was carried out at Altamash Institute of Dental Medicine, Pakistan, from April to May 2021. A total of 400 parents were recruited. An online self-administered questionnaire was circulated to the parents after taking the informed consent. 17 questions regarding demographics, knowledge and attitude were included. Chi-square test was used for association between demographics and responses of the participants.
\end{abstract}

Results: Of the 400 participants, there were $140(35 \%)$ males and 260 $(65 \%)$ females. Most of the $180(45 \%)$ participants belonged to $18-30$ years age bracket. About $63 \%$ of the children did not have past dental trauma history. Predominantly, $80 \%$ chose dentists being most appropriate of emergency treatment. 33\% believed to visit the dentist within 30minutes for treatment. About $50 \%$ participants agreed avulsed teeth can be placed back into its original position. More than half knew different transport mediums, with milk (21\%) and Hanks Balanced Salt Solution (19\%) being commonly selected. Younger age group and females were more knowledgeable regarding emergency management.

Conclusion: Dental avulsion is a common finding in childhood, which mandates proper knowledge for the guardians. There is still a gap present in adequate knowledge for management of such emergencies which mandates organizations of education and awareness programs for both children and adults.

Keywords: Attitude, Avulsed Teeth, Dental Trauma, Emergency, Knowledge.

\section{INTRODUCTION}

Traumatic dental injuries are one of the most common injuries that children suffer from that causes pain and stress, with dental avulsion being one of the commonest [1]. Avulsion of teeth or Dental Avulsion is defined as the complete removal/knocking of the teeth out of their socket. Most of the time, children usually encounter such traumatic dental injuries in their daily activities such as running, playing sports, cycling, etc. Maxillary Central Incisors are the most common teeth to experience dental avulsion during childhood [2]. The suggested reason for avulsion of these teeth particularly is that loosely structured periodontal ligament that surrounds the erupting tooth often manifests incompletely formed short roots along with the elasticity of the alveolar bone favours avulsion of these teeth [3]. While keeping gender in mind, such traumatic dental injuries are more common in boys as compared to girls, primarily due to boys being more involved in outdoor activities and sports [4].

When such injuries are encountered by children, not only do they face functional disabilities as they are fear to eat with compromised esthetics.
Published Online: October 31, 2021

ISSN: $2684-4443$

DOI : $10.24018 /$ ejdent.2021.2.5.99

\section{Hira Abbasi}

Department of Operative Dentistry, Altamash Institute of Dental Medicine, Pakistan.

(e-mail: drhirabbasi@gmail.com)

Abhishek Lal *

Department of Operative Dentistry, Altamash Institute of Dental Medicine, Pakistan.

(e-mail: abhishekdarshan ${ }^{\circledR}$ yahoo.com) Ammara Shamim Jaffrani

Department of Operative Dentistry, Altamash Institute of Dental Medicine, Pakistan.

(e-mail: ammarajaffrani@ ${ }^{\circledR}$ hotmail.com)

*Corresponding Author

broken teeth, but they face psychological disturbances too. In order to achieve a good prognosis for the children, immediate treatment such as replantation of the avulsed teeth is required. But at times, if the time of replantation is delayed, it is of vital importance to keep the periodontal ligament of the avulsed tooth viable in order to facilitate replantation and achieve favourable prognosis [5].

Dental avulsion affects different aspects of life such as esthetics, psychological and functional, which has its consequences on both the parents as well as their children. Avulsion of primary teeth tends to have little impact on children and parents as these milk/primary teeth are bound to be avulsed on their due time and will be superseded by permanent teeth, so their early avulsion has little impact [6]. However, such injuries to permanent teeth have a great effect on children and teenagers. When children go through such an unfortunate incident, they avoid smiling of because of

There are different treatment options that are available to deal with the avulsed teeth and the associated factors such as the viability of periodontal ligament, delayed reimplantation, 
and unphysiological storage mediums affect the choice of treatment for the patient [7]. It has been shown that teeth that are replanted back in their socket with the extra-alveolar time of within 1 hour offers higher functional healing and better prognosis [8].

The primary reason for the unfavourable prognosis of the avulsed teeth of children is due to a lack of knowledge and attitude as to how to deal with the situation [9]. Furthermore, it's of vital importance for the parents or guardians to have adequate knowledge and attitude towards the avulsed teeth of their children so that their timely reaction can offer better and optimum treatment options for their children [10].

Therefore, this study aims to assess the levels of knowledge and attitude of guardians/parents regarding the avulsion of primary and permanent teeth of their children, its emergency management, and immediate steps that are to be taken when such incidents occur.

\section{MATERIALS AND METHODS}

A cross-sectional survey-based study was carried out in the department of paediatric dentistry, of Altamash Institute of Dental Medicine, Pakistan. Using a simple random sampling method, a total of 550 responses from the parents were received and analyzed throughout Pakistan. The study was carried out from April to May 2021. Using Google Forms, a self-administered questionnaire was formulated which consisted of 3 parts: 1) Demographic Data, 2) Questions regarding knowledge of dental avulsion, and 3) Questions regarding attitudes towards dental avulsion. This wellstructured questionnaire was circulated to the parents throughout Pakistan using different social media platforms such as Facebook, WhatsApp, Twitter, and Emails. To determine the sample size for this study, OpenEpi software was used, keeping the desired percentile at 50 and a confidence interval of $95 \%$. The calculated sample size came out to be 345 participants ( $n=[Z 12-\alpha / 2 . p . q] / d 2)$ [11]. Before the participants took part in this study, they were made to read and sign the consent statement to ensure voluntary participation in this study.

The first part of the questionnaire consisted of demographics characteristics of the participants which included age, gender, and level of education. The second part of the questionnaire consisted of 9 questions assessing the knowledge of the parents regarding dental avulsions such as if their child has experienced dental avulsion, who would they take their child to for emergency treatment, how to stop the bleeding of the tooth socket, whether according to them the avulsed tooth is milk or permanent tooth if they can place the tooth back in their socket, and knowledge of different transport medium for the storage of the avulsed teeth. The third part of the questionnaire evaluated the attitude of the parents towards dental avulsion with 5 questions such as how quickly should they visit the dentist, whether they will look around for the avulsed tooth or ignore it if they can place the tooth back in the socket how will they treat the tooth before placement, should parents and children be taught about how to better deal with dental avulsion for a better prognosis for their children.

Before the start of this study, ethical consent was obtained from the Ethical Review Committee. Participation in this study was based on participants who were parents and above 18 years of age. The questionnaire was in English language and checked by all the authors of this study belonging to the same department as to ratify the study. Those who were not able to read and write were excluded from this study.

\section{STATISTICAL ANALYSIS}

For data analysis, Statistical Package for Social Sciences (SPSS) version 25 was used. Descriptive statistics along with a Chi-square test was used to analyze the association between age, gender, and level of education of the participants with their responses to the questions of the questionnaire. A pvalue of $\leq 0.05$ was considered to be statistically significant.

\section{RESULTS}

Out of 550 participants to whom the questionnaire was sent, 400 filled were analyzed and included in this study. The rest were excluded based on being partially filled and irrelevance. Of the 400 participants, there were $140(35 \%)$ males and $260(65 \%)$ females. Most of the $180(45 \%)$ participants belonged to the age bracket of $18-30$ years of age with graduate (46\%) and postgraduate (29\%) being the commonest of the level of education, as presented in Table I.

TABLE I: DEMOGRAPHIC CHARACTERISTICS OF THE PARTICIPANTS

\begin{tabular}{lcc}
\multicolumn{1}{c}{ Variables } & Frequency & Percentage $(\%)$ \\
\hline Age & & \\
18-30 years & 180 & 45.0 \\
31-40 years & 96 & 24.0 \\
41-50 years & 60 & 15.0 \\
51-60 years old & 40 & 10.0 \\
Above 60 years & 24 & 6.0 \\
Gender & & \\
Male & 140 & 35.0 \\
Female & 260 & 65.0 \\
Education & & \\
Undergraduate & 56 & 14.0 \\
Graduate & 184 & 46.0 \\
Postgraduate & 116 & 29.0 \\
Below Undergraduate & 44 & 11.0 \\
\hline
\end{tabular}

\section{A. Knowledge regarding Dental Avulsion}

When asked about their children experiencing any past dental trauma, the majority of $252(63 \%)$ parents said "No". When the teeth have been knocked out, most of the $268(67 \%)$ participants reported searching the ground for the knockedout teeth. The hospital was chosen as the first choice for the visit if the child feels unwell by 192 (48\%) participants, followed closely by 152 (38\%) who chose dental surgeon as their first choice. Predominantly, a majority of 320 (80\%) of the parents chose a dental surgeon as the most appropriate choice for the emergency management of the avulsed teeth. Regarding the timing of replantation of the teeth back in the socket, 140 (35\%) chose "immediately" and 132 (33.3\%) chose "when visiting the dentist" as appropriate choices. About the urgency to visit the dentist for treatment of their child, 132 (33\%) parents opted for "within 30 minutes" and $108(27 \%)$ went for "within 1 hour". To identify the type of teeth by the parents, $164(41 \%)$ selected milk/baby teeth and $156(39 \%)$ selected permanent teeth, while the remaining being uncertain about it. Just over $50 \%$ of the participants 
knew the different transport medium for carrying the avulsed teeth, with milk (21\%) and Hanks Balanced Salt Solution (19\%) being the commonly chosen ones according to the parent's knowledge.

\section{B. Attitudes regarding Dental Avulsion}

About replacement of the knocked-out tooth back into the socket, half of the participants agreed it can be placed back into its original position, although about 232 (58\%) do not know how to place it back into the socket. The ones who believed to have the skills to put the teeth back into the socket, washing the tooth with water was considered to be performed first before placing it back by $136(44.2 \%)$ of the parents. The majority of $320(80 \%)$ of the parents considered that educational programs regarding dental trauma should be taught to their children along with themselves to gain knowledge for better emergency management in such situations.

\section{Association of Demographics with Knowledge and Attitude}

Parents who belonged to the younger age group showed to have more knowledge ( $\mathrm{p}$-value $=0.00$ ) and a positive attitude (p-value $=0.00)$ about the management of dental avulsion of their children, as shown in Table II. Regarding gender, females tend to be more knowledgeable as compared to males for management of dental avulsion ( $p$-value $=0.00$ ), as presented in Table III. Lastly for the level of education, the higher the educational level, the better the knowledge (pvalue $=0.00)$ and attitude ( $\mathrm{p}$-value $=0.00)$ parents had to handle such emergencies as shown in Table IV.

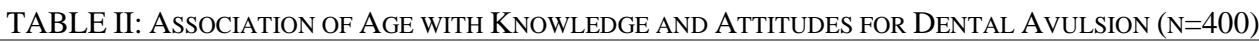

\begin{tabular}{|c|c|c|c|c|c|c|c|}
\hline Questions & Answers & $\begin{array}{l}18-30 \\
\text { years }\end{array}$ & $\begin{array}{l}31-40 \\
\text { years }\end{array}$ & $\begin{array}{l}41-50 \\
\text { years }\end{array}$ & $\begin{array}{l}51-60 \\
\text { years }\end{array}$ & $\begin{array}{c}\text { Above } 60 \\
\text { years }\end{array}$ & P-value \\
\hline \multicolumn{8}{|c|}{ Questions about Knowledge } \\
\hline \multirow[t]{2}{*}{ Past dental Trauma } & Yes & 40 & 48 & 28 & 16 & 16 & \multirow{2}{*}{0.000} \\
\hline & No & 140 & 48 & 32 & 24 & 8 & \\
\hline \multirow[t]{2}{*}{ Search the ground for tooth } & Yes & 140 & 52 & 40 & 20 & 16 & \multirow{2}{*}{0.000} \\
\hline & No & 40 & 44 & 20 & 20 & 8 & \\
\hline \multirow{4}{*}{$\begin{array}{l}\text { First place to visit if child is } \\
\text { unwell }\end{array}$} & Home & 12 & 0 & 0 & 8 & 0 & \multirow{4}{*}{0.000} \\
\hline & Hospital & 84 & 48 & 32 & 16 & 12 & \\
\hline & Dental surgeon & 64 & 44 & 20 & 12 & 12 & \\
\hline & I don't know & 20 & 4 & 8 & 4 & 24 & \\
\hline \multirow[t]{3}{*}{ Emergency management } & Dental Surgeon & 156 & 72 & 48 & 28 & 16 & \multirow{3}{*}{0.000} \\
\hline & Medical Doctor & 16 & 16 & 4 & 12 & 8 & \\
\hline & I don't know & 8 & 4 & 8 & 0 & 0 & \\
\hline \multirow{6}{*}{$\begin{array}{l}\text { Time to tooth placement back } \\
\text { into socket }\end{array}$} & Immediately & 84 & 16 & 24 & 16 & 0 & \multirow{6}{*}{0.000} \\
\hline & When the bleeding stops & 20 & 20 & 0 & 4 & 8 & \\
\hline & During first hour & 24 & 0 & 4 & 0 & 0 & \\
\hline & First 6 hours & 4 & 8 & 8 & 0 & 4 & \\
\hline & Within 24 hours & 12 & 0 & 0 & 0 & 8 & \\
\hline & When visiting the Dentist & 36 & 48 & 24 & 20 & 4 & \\
\hline \multirow[t]{5}{*}{ When to visit the dentist } & Within 30mins & 76 & 32 & 8 & 4 & 12 & \multirow{5}{*}{0.000} \\
\hline & Within 1 hour & 48 & 12 & 36 & 12 & 0 & \\
\hline & Within 24 hours & 44 & 24 & 4 & 4 & 4 & \\
\hline & Next day & 4 & 0 & 0 & 4 & 0 & \\
\hline & No visit to the dentist required & 8 & 28 & 12 & 16 & 8 & \\
\hline \multirow[t]{3}{*}{ Broken tooth likely to be } & Milk/Baby tooth & 80 & 64 & 12 & 4 & 4 & \multirow{3}{*}{0.000} \\
\hline & Permanent tooth & 56 & 28 & 36 & 24 & 12 & \\
\hline & I don't know & 44 & 4 & 12 & 12 & 8 & \\
\hline \multirow{2}{*}{$\begin{array}{l}\text { Aware of different transport } \\
\text { media }\end{array}$} & Yes & 108 & 56 & 28 & 8 & 12 & \multirow{2}{*}{0.000} \\
\hline & No & 72 & 40 & 32 & 32 & 12 & \\
\hline \multirow[t]{5}{*}{ Best transport media } & Water & 12 & 16 & 8 & 8 & 4 & \multirow{5}{*}{0.000} \\
\hline & Milk & 44 & 24 & 12 & 4 & 0 & \\
\hline & Saliva & 16 & 4 & 0 & 0 & 8 & \\
\hline & Hanks Balanced Salt Solution & 52 & 12 & 8 & 4 & 0 & \\
\hline & I don't know & 28 & 20 & 16 & 4 & 4 & \\
\hline & Ques & Attitud & & & & & \\
\hline Teeth be placed back into & Yes & 120 & 36 & 32 & 8 & 4 & \\
\hline socket & No & 36 & 20 & 4 & 24 & 16 & 0.000 \\
\hline & Maybe & 24 & 40 & 24 & 8 & 4 & \\
\hline Can you place the tooth back & Yes & 96 & 24 & 24 & 16 & 8 & \\
\hline & No & 84 & 72 & 36 & 24 & 16 & 0.000 \\
\hline Pre-placement tooth & Wash it with water & 68 & 28 & 24 & 8 & 8 & \\
\hline treatment & Clean it with a cloth & 12 & 0 & 4 & 0 & 0 & \\
\hline & Brush the tooth & 4 & 8 & 0 & 0 & 0 & \\
\hline & Place it back without doing anything & 40 & 8 & 0 & 8 & 0 & 0.000 \\
\hline & I don't know & & & & & & \\
\hline & & 36 & 24 & 20 & 4 & 4 & \\
\hline Dental trauma education for & Yes & 164 & 76 & 40 & 24 & 16 & \\
\hline children & No & 12 & 4 & 4 & 4 & 0 & 0.000 \\
\hline & Maybe & 4 & 16 & 16 & 12 & 8 & \\
\hline Dental trauma programs for & Yes & 156 & 76 & 48 & 24 & 16 & \\
\hline adults & No & 12 & 4 & 0 & 8 & 0 & 0.000 \\
\hline & Maybe & 12 & 16 & 12 & 8 & 8 & \\
\hline
\end{tabular}


European Journal of Dental and Oral Health www.ejdent.org

TABLE III: AsSOCIATION OF GENDER WITH KNOWLEDGE AND ATTITUdES FOR DENTAL AvUlsion (N=400) Questions Answers Male Female

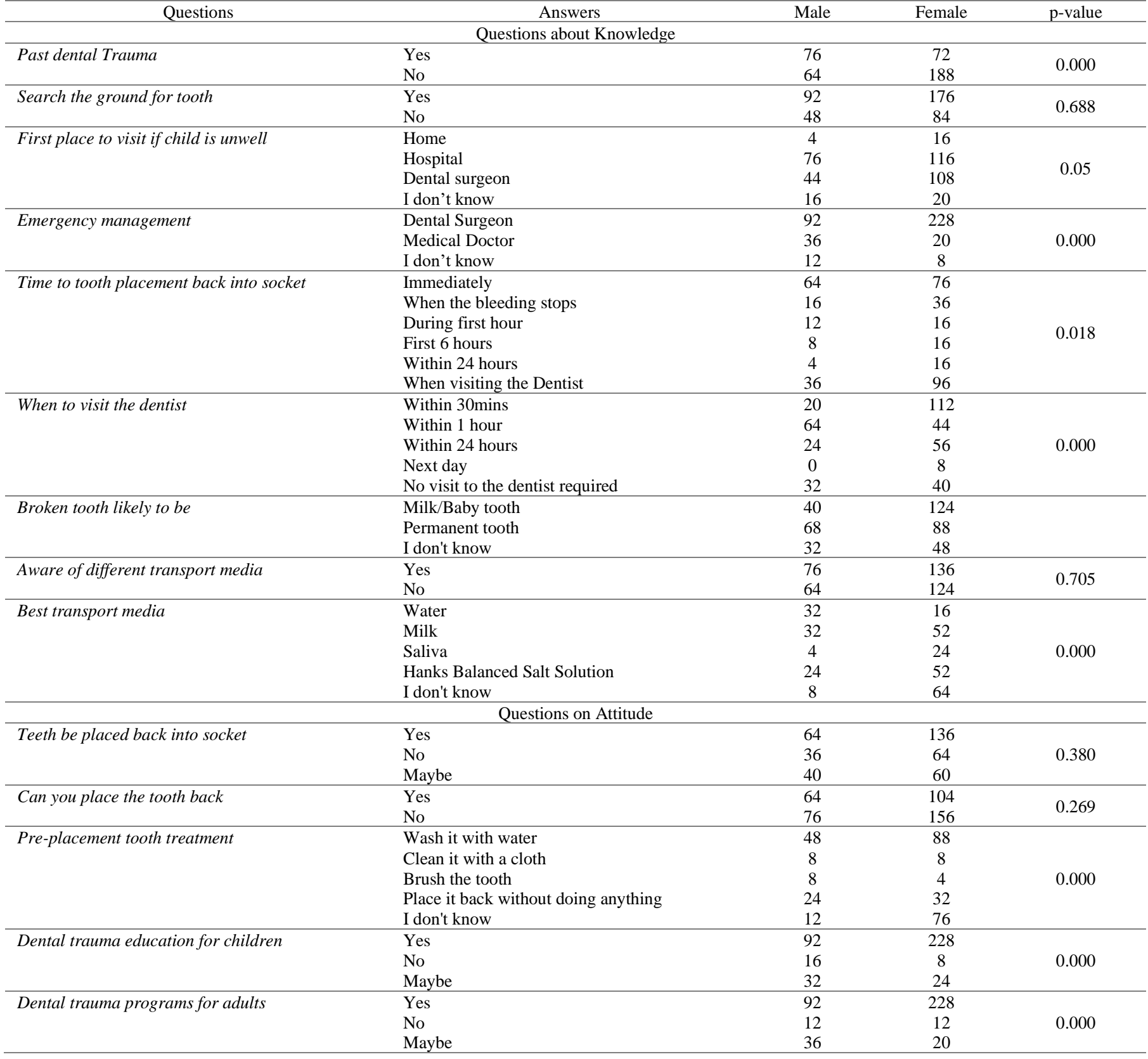

TABLE IV: AsSOCiation of EdUCATION WITH KNOWLEDGE AND ATTITUDES FOR DENTAL AvUlsion (N=400)

\begin{tabular}{|c|c|c|c|c|c|c|}
\hline Questions & Answers & Undergraduate & Graduate & Postgraduate & Below Undergraduate & P-value \\
\hline \multicolumn{7}{|c|}{ Questions about Knowledge } \\
\hline \multirow[t]{2}{*}{ Past dental Trauma } & Yes & 12 & 80 & 44 & 12 & \multirow{2}{*}{0.012} \\
\hline & No & 44 & 104 & 72 & 32 & \\
\hline \multirow{2}{*}{$\begin{array}{l}\text { Search the ground for } \\
\text { tooth }\end{array}$} & Yes & 28 & 132 & 100 & 8 & \multirow[t]{2}{*}{0.000} \\
\hline & No & 28 & 52 & 16 & 36 & \\
\hline \multirow{4}{*}{$\begin{array}{l}\text { First place to visit if } \\
\text { child is unwell }\end{array}$} & Home & 8 & 8 & 0 & 4 & \multirow{4}{*}{0.000} \\
\hline & Hospital & 16 & 100 & 56 & 20 & \\
\hline & Dental surgeon & 28 & 68 & 48 & 8 & \\
\hline & I don't know & 4 & 8 & 12 & 12 & \\
\hline \multirow[t]{3}{*}{ Emergency management } & Dental Surgeon & 44 & 164 & 92 & 20 & \multirow{3}{*}{0.000} \\
\hline & Medical Doctor & 12 & 20 & 12 & 12 & \\
\hline & I don't know & 0 & 0 & 8 & 12 & \\
\hline Time to tooth placement & Immediately & 12 & 80 & 40 & 8 & \multirow{8}{*}{0.000} \\
\hline \multirow[t]{7}{*}{ back into socket } & When the bleeding stops & 12 & 28 & 8 & 4 & \\
\hline & During first hour & & & & & \\
\hline & First 6 hours & 8 & 20 & 0 & 0 & \\
\hline & Within 24 hours & 0 & 0 & 24 & 0 & \\
\hline & When visiting the & 0 & 12 & 4 & 4 & \\
\hline & Dentist & & & & & \\
\hline & & 24 & 44 & 36 & 28 & \\
\hline \multirow[t]{2}{*}{ When to visit the dentist } & Within 30mins & 16 & 80 & 36 & 0 & \multirow{2}{*}{0.000} \\
\hline & Within 1 hour & 20 & 36 & 44 & 8 & \\
\hline
\end{tabular}




\begin{tabular}{|c|c|c|c|c|c|c|}
\hline Questions & Answers & Undergraduate & Graduate & Postgraduate & Below Undergraduate & P-value \\
\hline & Within 24 hours & 20 & 36 & 20 & 4 & \\
\hline & Next day & 0 & 0 & 0 & 8 & \\
\hline & $\begin{array}{l}\text { No visit to the dentist } \\
\text { required }\end{array}$ & 0 & 32 & 16 & 24 & \\
\hline \multirow[t]{3}{*}{ Broken tooth likely to be } & Milk/Baby tooth & 32 & 92 & 36 & 4 & \multirow{3}{*}{0.000} \\
\hline & Permanent tooth & 8 & 68 & 64 & 16 & \\
\hline & I don't know & 6 & 24 & 16 & 24 & \\
\hline \multirow{2}{*}{$\begin{array}{l}\text { Aware of different } \\
\text { transport media }\end{array}$} & Yes & 16 & 124 & 68 & 4 & \multirow{2}{*}{0.000} \\
\hline & No & 40 & 60 & 48 & 40 & \\
\hline \multirow[t]{6}{*}{ Best transport media } & Water & 4 & 28 & 4 & 12 & \multirow{6}{*}{0.000} \\
\hline & Milk & 4 & 44 & 28 & 8 & \\
\hline & Saliva & 4 & 20 & 4 & 0 & \\
\hline & Hanks Balanced Salt & 16 & 36 & 24 & 0 & \\
\hline & Solution & & & & & \\
\hline & I don't know & 20 & 16 & 36 & 20 & \\
\hline \multicolumn{7}{|c|}{ Questions on Attitude } \\
\hline \multirow{3}{*}{$\begin{array}{l}\text { Teeth be placed back } \\
\text { into socket }\end{array}$} & Yes & 36 & 96 & 68 & 0 & \multirow{3}{*}{0.000} \\
\hline & No & 8 & 48 & 20 & 24 & \\
\hline & Maybe & 12 & 40 & 28 & 20 & \\
\hline Can you place the tooth & Yes & 12 & 108 & 40 & 8 & \multirow{2}{*}{0.000} \\
\hline back & No & 44 & 76 & 76 & 36 & \\
\hline Pre-placement tooth & Wash it with water & 16 & 80 & 32 & 8 & \multirow{6}{*}{0.000} \\
\hline \multirow[t]{5}{*}{ treatment } & Clean it with a cloth & 0 & 4 & 8 & 4 & \\
\hline & Brush the tooth & & & & & \\
\hline & Place it back without & 0 & 8 & 4 & 0 & \\
\hline & doing anything & 8 & 28 & 20 & 0 & \\
\hline & I don't know & 28 & 28 & 32 & 12 & \\
\hline \multirow{3}{*}{$\begin{array}{l}\text { Dental trauma education } \\
\text { for children }\end{array}$} & Yes & 40 & 172 & 96 & 12 & \multirow{3}{*}{0.000} \\
\hline & No & 4 & 12 & 4 & 4 & \\
\hline & Maybe & 12 & 0 & 16 & 28 & \\
\hline \multirow{3}{*}{$\begin{array}{l}\text { Dental trauma programs } \\
\text { for adults }\end{array}$} & Yes & 44 & 168 & 92 & 16 & \multirow{3}{*}{0.000} \\
\hline & No & 4 & 12 & 4 & 4 & \\
\hline & Maybe & 8 & 4 & 20 & 24 & \\
\hline
\end{tabular}

\section{DISCUSSION}

In this cross-sectional study, we assessed the knowledge and attitude of the guardians regarding the management of avulsion of the primary and permanent teeth of their children. Dental trauma such as avulsion has a major impact on the functional and esthetic needs of the children. So, therefore proper knowledge of the management of the avulsed teeth is important for the guardians.

Dental avulsion is one of the most common types of dental trauma and the prognosis of such teeth mainly depends on the timely management of the teeth such as steps taken to preserve the teeth and timely visits to the dental surgeon for favorable treatment options such as replantation. In our study, $37 \%$ of the parents reported having children suffering from dental avulsion with $67 \%$ of them searching for the teeth around in the ground. These results are significantly higher than the previous studies where only $24.8 \%$ searched for the missing teeth [12]. The difference in results primarily is due to the level of education amongst the participants of the two studies.

After the dental avulsion, children may at times feel dizzy and unwell due to loss of blood and unfamiliar incident happening to them. In our study, $48 \%$ of parents of the parents chose hospital as the first place to visit in such a scenario, with $38 \%$ opting for the dental surgeon. These results are significantly higher than previous studies in the literature [11]. Lack of knowledge plays a fundamental role in deciding the primary care for children in such incidents.

After the tooth has been avulsed, the time taken to place it back in the socket is one of the primary factors affecting the prognosis. In this study, immediately (35\%) and when visiting the dentist (33\%) were commonly chosen options.
These results contrast with one study by Santos reporting 99\% of the respondents seeking the immediate care of the avulsed teeth [13]. Lack of awareness of proper knowledge of dental trauma mainly is the reason for such cases.

After the teeth have been avulsed, the parents should visit the dentist as soon as possible in order to maximize their chances of better treatment options for their children. Our study reported within 30 minutes $(33 \%)$ and within 1 hour $(37 \%)$ as the necessary time to visit the dentist. However, a study by Unal et al. reported that the time taken from avulsion to visiting the dentist exceeded more than 60 minutes [14]. So, the greater the time is taken to visit the dentist, the poorer the prognosis gets for the avulsed tooth, which might ultimately be replanted back.

Knocking of both milk and permanent teeth is a common finding during the early years of childhood, with maxillary central incisors being among the commonest ones to get affected. $41 \%$ of the respondents believed the avulsed teeth to be milk teeth whereas $39 \%$ considering them as permanent teeth and few not being sure about it. After the avulsion of teeth, in order to carry it safely for replantation to the dentist, a proper storage medium is required. About 53\% of the parents had some knowledge about the different transport mediums that are available. Milk (27.3\%) and Hanks Balanced Salt Solution (24.7\%) were the commonly chosen options. These results correspond with the studies in the literature which reports similar findings as milk being commonly used transport medium [15], [16]. Milk is available nearly in every household due to its low cost, high rate of consumption, and easy availability along with its properties to preserve PDL cells viability [17]. Since it preserves and provides necessary nutrition for the PDL to survive, it can be used as a transport medium to carry the avulsed tooth. Although according to studies carried out, the 
best transport medium for the avulsed teeth is the Hanks Balanced Salt Solution, which although is not well known due to lack of knowledge regarding dental traumas among the general population [18], [19].

Placement of the avulsed teeth back into the socket and on time is important to maintain its favourable prognosis. More than half of the parents in this study did not believe that the tooth can be placed back into the socket. Furthermore, those who thought the teeth can be placed back, $58 \%$ of the participants did not have the necessary skills to place it back. Such findings are reported in one study where less than $50 \%$ did not know how to place the avulsed tooth back [20]. However, these results contrast with studies carried out in the literature where $65 \%$ of the participants knew how to place it back into the socket [21]. Before placement of the tooth back into the socket, proper handling is important to preserve the PDL. In this study majority (34\%) of parents thought washing with water was the ideal step before reimplantation of the tooth. According to the International Association of Dental Traumatology (IADT), the avulsed teeth should be briefly washed for not more than 10 seconds under cold water at the site of dental avulsion [22].

For the proper management of such dental avulsion injuries, proper education programs for the children as well as the adults should be organized so that teeth that can be salvaged, should be salvaged to prevent the child from undergoing unnecessary further dental treatment. Dental treatments for children are already a situation full of anxiety due to various instrumentations and treatments going around them, so such anxiety management should be essential for children, dentists, and the parents themselves too [23].

\section{LIMITATIONS}

Although this study highlights the importance of proper knowledge and attitudes of the parents for dental avulsion of their children, but it was met with some limitations. Firstly, this study included a small number of individuals, a larger number of individuals would provide better insight. Lastly, the inclusion of more participants from the rural areas would provide better levels of knowledge and attitude as there is more negligence of dental treatments is such population.

\section{CONCLUSION}

Many children face dental avulsion during their childhood, which affects their esthetic, psychological, and functional well-being. Since the guardians or parents are at many times in the immediate vicinity when such incidents occur, they should have the proper knowledge to handle such emergencies. A knowledge gap is still present by concluding the findings of this study as there is still a lack of adequate knowledge and attitude for emergency management of dental avulsion of children. Educational and awareness programs are needed, especially in the rural areas.

\section{ACKNOWLEDGMENT}

The authors of this study would like the thank all of the participants for their collaboration, support and cooperation in this study.

\section{REFERENCES}

[1] A. Topaloglu, D.O. Ozdas, S. Zorlu, P.K. Karataban, "Dental Traumatology in Pediatric Dentistry. In: Trauma in Dentistry" [Internet]. IntechOpen; 2019. Available from https://www.intechopen.com/books/trauma-in-dentistry/dentaltraumatology-in-pediatric-dentistry.

[2] S. Alotaibi, A. Haftel, N.D. Wagner, "Avulsed Tooth" [Internet]. StatPearls. 2021.

[3] S. Petti, G .Tarsitani, "Traumatic injuries to anterior teeth in Italian schoolchildren: prevalence and risk factors". Dentla Traumatology [Internet]. 1996 Dec 12(6):294-7. Available from: http://doi.wiley.com/10.1111/j.1600-9657.1996.tb00530.x.

[4] T.R.C. Soares, L.A. Jural, I. Sant'Ana, R.R. Luiz, L.A.A. Antunes, P.de.A. Risso, et al. "Risk Factors for Different Types of Traumatic Injuries in Primary Teeth," Pesqui Bras Odontopediatria Clin Integr, [Internet]. 2020;20.

[5] B.I. Aslan, N. Üçüncü. "Clinical Consideration and Management of Impacted Maxillary Canine Teeth. In: Emerging Trends in Oral Health Sciences and Dentistry [Internet]," InTech; 2015. Available from http://www.intechopen.com/books/emerging-trends-in-oral-healthsciences-and-dentistry/clinical-consideration-and-management-ofimpacted-maxillary-canine-teeth/.

[6] M.P. Araujo, S. Uribe, M.D. Robertson, F.M. Mendes, D.P. Raggio, N.P.T. Innes, "The Hall Technique and exfoliation of primary teeth: a retrospective cohort study," $\mathrm{Br}$ Dent J [Internet]. 2020 Feb $14 ; 228(3): 213-7$.

[7] V.I. Khinda, G.S. Brar, S. Kallar, H. Khurana, "Clinical and Practical Implications of Storage Media used for Tooth Avulsion," Int J Clin Pediatr Dent, [Internet]. 2017 Jun 10(2):158-65. Available from: https://www.ijcpd.com/doi/10.5005/jp-journals-10005-1427/.

[8] G. Wang, C. Wang, M. Qin, "A retrospective study of survival of 196 replanted permanent teeth in children," Dent Traumatol, [Internet] 2019 Oct, vol. 29; 35(4-5):251-8. Available from https://onlinelibrary.wiley.com/doi/abs/10.1111/edt.12475.

[9] D.D. Müller, R. Bissinger, M. Reymus, K. Bücher, R. Hickel, J .Kühnisch, "Survival and complication analyses of avulsed and replanted permanent teeth," Sci Rep, [Internet]. 2020 Dec $18 ; 10(1): 2841$

[10] N.M. AlGhamdi, S. Alothman, A. Assiri, M.A. Bijle, R. Togoo, "Knowledge of Saudi parents toward the emergency management of avulsed permanent teeth: A cross-sectional survey," J Dent Res Rev [Internet]. 2016;3(3):85.

[11] A. Jain, P. Kulkarni, S. Kumar, M. Jain, "Knowledge and Attitude of Parents towards Avulsed Permanent Tooth of their Children and its Emergency Management in Bhopal City," J Clin Diagn Res [Internet]. 2017 May;11(5):ZC40-4.

[12] S. Shamarao, S. Tikare, S. Ajagannanavar, R. Haridas, J. Jain, A. Kalappa, "Knowledge and attitude regarding management of tooth avulsion injuries among school teachers in rural India," J Int Soc Prev Community Dent [Internet]. 2014;4(4):44. Available from: http://www.jispcd.org/text.asp?2014/4/4/44/144599.

[13] M.E.S.M. Santos, A.P.Z. Habecost, F.V. Gomes, J.B.B. Weber, M.G. de Oliveira, "Parent and caretaker knowledge about avulsion of permanent teeth," Dent Traumatol [Internet]. 2009 Apr;25(2):203-8.

[14] M. Unal, F. Oznurhan, A. Kapdan, S. Aksoy, A. Dürer, "Traumatic dental injuries in children. Experience of a hospital in the central Anatolia region of Turkey," Eur J Paediatr Dent [Internet]. 2014 Mar;15(1):17-22.

[15] A. Hamid, A. Carter, "Tooth avulsion: does the milk matter?," Br Dent J [Internet]. 2021 Mar 26;230(6):326-326. Available from: http://www.nature.com/articles/s41415-021-2859-5.

[16] L.M. Côvre, E.A. Caliente, C.K. Sonoda, D.A. Brandini, W.R. Poi, "The effect of soy and whole milk as a means to store avulsed teeth: A histometric study," Dent Traumatol [Internet]. 2021 Feb 24;37(1):819.

[17] L.A. Bahammam, "Knowledge and attitude of emergency physician about the emergency management of tooth avulsion," BMC Oral Health [Internet]. 2018 Dec 2;18(1):57. Available from: https://bmcoralhealth.biomedcentral.com/articles/10.1186/s12903018-0515-5.

[18] S. Adnan, M.M. Lone, F.R. Khan, S.M. Hussain, S.E. Nagi, "Which is the most recommended medium for the storage and transport of avulsed teeth? A systematic review," Dent Traumatol [Internet]. 2018 Apr;34(2):59-70.

[19] N.C.F. Fagundes, L.O. Bittencourt, M.B. Magno, M.M. Marques, L.C. Maia, R.R. Lima, "Efficacy of Hank's balanced salt solution compared to other solutions in the preservation of the periodontal ligament. A systematic review and meta-analysis," Topcuoglu N, editor. PLoS One 
[Internet]. 2018 Jul 13;13(7):e0200467. Available from: https://dx.plos.org/10.1371/journal.pone.0200467.

[20] Z. Uzarevic, Z. Ivanisevic, M. Karl, M. Tukara, D. Karl, M. Matijevic, "Knowledge on Pre-Hospital Emergency Management of Tooth Avulsion among Croatian Students of the Faculty of Education," Int J Environ Res Public Health [Internet]. 2020 Sep 30;17(19):7159. Available from: https://www.mdpi.com/1660-4601/17/19/7159.

[21] A.P. Nikam, M.D. Kathariya, K. Chopra, A. Gupta, R. Kathariya, "Knowledge and Attitude of Parents/Caretakers toward Management of Avulsed Tooth in Maharashtrian Population: A Questionnaire Method," J Int oral Heal JIOH [Internet]. 2014 Sep;6(5):1-4. Available from: http://www.ncbi.nlm.nih.gov/pubmed/25395784.

[22] L. Andersson, J.O. Andreasen, P. Day, G. Heithersay, M. Trope, A.J. DiAngelis, et al, "International Association of Dental Traumatology guidelines for the management of traumatic dental injuries: 2. Avulsion of permanent teeth," Dent Traumatol [Internet]. 2012 Apr;28(2):88-96.

[23] H. Abbasi, M. Saqib, R. Jouhar, A. Lal, N. Ahmed, M.A. Ahmed, M.K Alam, "The Efficacy of Little Lovely Dentist, Dental Song, and TellShow-Do Techniques in Alleviating Dental Anxiety in Paediatric Patients: A Clinical Trial," Biomed Research International, 2021 May $23 ; 2021: 1-7$ 